\title{
BONE MARROW PRESSURE IN LEUKEMIC AND NON-LEUKEMIC PATIENTS
}

\author{
By NICHOLAS L. PETRAKIS \\ (From the Laboratory of Experimental Oncology, National Cancer Institute, National Institutes \\ of Health, Public Health Service, Department of Health, Education and Welfare; and \\ the Department of Medicine and Cancer Research Institute, University of Californio \\ School of Medicine, San Francisco, Calif.)
}

(Submitted for publication July 20, 1953 ; accepted September 18, 1953)

It has been a frequent observation that many patients with leukemia and multiple myeloma bleed freely through the marrow needle at the time of bone marrow aspiration although hemorrhagic tendencies may not be present clinically. In addition, throbbing bone pain and bone tenderness are not infrequently observed in these patients (1). Such clinical observations suggest that some degree of pressure elevation may be present in the marrow cavity in these diseases. It was believed of interest to determine the pressure relationships within the human marrow cavity under a variety of physiologic stimuli.

\section{MATERIALS AND METHODS}

The marrow pressures of 14 patients with neoplastic diseases having essentially normal marrows, as determined by microscopic examination, and of 10 patients with leukemia and one patient with multiple myeloma were determined by means of recording strain gauges attached to clinical bone marrow needles. The patients were studied under resting but not basal conditions, without previous sedation. The pressure in both the sternal and iliac crest marrows was measured in most patients, either simultaneously or serially. The sternal site was at the level of the second interspace, and the iliac crest at a site two centimeters posterior to the anterior superior iliac spine. The usual precautions of sterility and local procaine anesthesia of skin and periosteum were employed.

A bonded SR4 wire resistance strain gauge and recording apparatus developed for clinical pressure measurements by Bierman and Jenkins (2) were employed for pressure determinations. The gauge was connected directly to the bone marrow needle after the needle and gauge chamber had been filled with heparin-saline solution. The saline within the manometer was equalized with the ambient pressure, after which the chamber was sealed. The output of the strain gauge was connected to a strain indicator and photographically recorded with a multiple channel recording oscilloscope.

The Turkel-Bethell bone marrow needle employed in these studies had a 14-gauge bore and was equipped with a trephine stylette which made it useful for removing bony spicules which frequently entered the needle during its implantation. After implantation, the needle was filled with heparin-saline solution, care being exercised to exclude air bubbles. It was found necessary to premedicate the patients with 50 to $100 \mathrm{mg}$. of heparin intravenously shortly before the studies to prevent clotting within the needle in the marrow. Smaller amounts of heparin were used in patients with leukemia, or completely omitted where manifest bleeding tendencies existed.

A modified strain gauge strapped over the lower chest cage was utilized as a pneumotachometer, and a single lead EKG tracing was made in each patient for pulse determinations. The marow pressure, respiratory rate and amplitude, and EKG record were simultaneously recorded photographically.

The marrow pressures were studied with the patients at rest in supine position, during exaggerated respiration, coughing, Valsalva and Mueller maneuvers, changes of body position, and following the injection of epinephrine. The Valsalva studies were roughly standardized by having the patients blow against a mercury manometer at 40 $\mathrm{mm}$. Hg pressure.

Bone marrow for cytological examination was aspirated from each site studied at the conclusion of the pressure studies. An estimate of cellularity of the smears was attempted in each patient and recorded as normal, decreased, or increased, although it was recognized that this type of estimation may be markedly in error. The time required for the usual study averaged 30 to 45 minutes. Aside from the usual initial discomfort resulting from anesthetization of the skin and periosteum, and implantation of the marrow needle, no pain or discomfort was experienced by the patients during the pressure determinations.

\section{RESULTS}

The resting marrow pressures for all patients, with age, sex, diagnosis, hemoglobin level, and blood pressure, are shown in Table I. The patients can be divided upon the basis of the presence or absence of marrow disease. The marrows of the non-leukemic and lymphoma patients did not contain metastatic carcinoma or lymphomatous involvement, as ascertained by microscopic examination, and were of normal cellularity in all patients, except in J. K. where decreased cellularity was found. Most of the leukemic patients had increased cellularity of the marrow (Table I). 
A. Non-leukemic marrows having no demonstrable tumor cells

The pressures in the marrows of patients without marrow diseases, including the lymphoma group, were found to be uniformly low. In the sternum the pressures were approximately atmospheric or slightly negative ranging from $2 / 0$ to $17 / 15 \mathrm{~mm}$. $\mathrm{Hg}$. The sternal pressures frequently were observed to vary with the depth of respirations, while no effect of respirations was observed in the more distal iliac crest site. Figure 1 demonstrates a typical pressure recording made on the sternal and iliac crest marrow in a patient with Xanthomatosis, without cytological or peripheral hematologic evidence of marrow dysfunction.

The typical effect of the Valsalva maneuver is shown in Figure 1. In this patient both marrow sites demonstrated a prompt pressure rise when the patient expired against a mercury column of $40 \mathrm{~mm} . \mathrm{Hg}$. The usual pressure increase ranged from 10 to $60 \mathrm{~mm}$. $\mathrm{Hg}$. The Mueller maneuver, in most patients, resulted in a decided negative sternal pressure, varying from -10 to $-30 \mathrm{~mm}$. $\mathrm{Hg}$ and occurring concomitantly with the greater

\begin{tabular}{|c|c|c|c|c|c|c|c|c|c|}
\hline Patient & Age & Sex & Diagnosis & $\begin{array}{l}\text { Hemo- } \\
\text { globin }\end{array}$ & $\begin{array}{c}\text { Relative } \\
\text { marrow } \\
\text { cellu- } \\
\text { larity* }\end{array}$ & $\begin{array}{l}\text { Brachial } \\
\text { artery } \\
\text { cuff } \\
\text { pressure }\end{array}$ & $\begin{array}{l}\text { Sterr } \\
\text { marr } \\
\text { press }\end{array}$ & & $\underset{\substack{\text { Iliac } \\
\text { pressuw }}}{\text { pressure }}$ \\
\hline O. H. & 47 & M & Carcinoma of lung & $\begin{array}{c}\text { Gm. \% } \\
9.0\end{array}$ & $\mathrm{~N}$ & $\frac{120}{80}$ & $m m$. & $\begin{array}{l}H_{g} \\
\frac{4}{2}\end{array}$ & $\begin{array}{c}m m . \mathrm{Hg} \\
-\end{array}$ \\
\hline J. M. & 51 & $\mathbf{M}$ & Carcinoma of lung & 10.7 & $\mathbf{N}$ & $\frac{105}{70}$ & & $\frac{-2}{-3}$ & $\frac{11}{10}$ \\
\hline M. M. & 49 & $\mathbf{M}$ & Epithelioma of lip & 14.4 & $\mathrm{~N}$ & $\frac{170}{110}$ & $\frac{0}{-1}$ to & $\frac{-5}{-6}$ & - \\
\hline O. U. & 40 & $\mathbf{M}$ & Xanthomatosis & 9.9 & $\mathrm{~N}$ & $\frac{115}{75}$ & & $\frac{-1}{-3}$ & $\frac{2}{1}$ \\
\hline H. K. & 44 & $\mathbf{M}$ & Carcinoma of pancreas & 11.2 & $\mathbf{N}$ & $\frac{110}{80}$ & - & & $\frac{10}{5}$ \\
\hline G. R. & 59 & $\mathbf{M}$ & Melanoma & 12.9 & $\mathbf{N}$ & $\frac{150}{80}$ & - & & $\frac{2}{0}$ \\
\hline A. L. & 47 & $\mathbf{M}$ & Melanoma & 8.9 & $\mathbf{N}$ & $\frac{147}{85}$ & - & & $\frac{5}{2}$ \\
\hline A. B. & 38 & M & Melanoma & 9.6 & $\mathrm{~N}$ & $\frac{140}{88}$ & - & & $\frac{15}{10}$ \\
\hline J. K. & 63 & $\mathbf{M}$ & Melanoma & 14.7 & $\mathrm{D}$ & $\frac{120}{80}$ & - & & $\frac{17}{15}$ \\
\hline I. R. & 23 & M & Lymphosarcoma & 14.0 & $\mathrm{~N}$ & $\frac{120}{75}$ & & $\frac{-2}{-3}$ & $\begin{array}{l}7 \\
\frac{7}{4}\end{array}$ \\
\hline J. H. & 68 & M & Lymphosarcoma & 13.7 & $\mathrm{~N}$ & $\frac{125}{80}$ & $\frac{0}{-1}$ to & $\frac{-5}{-6}$ & $\frac{8}{5}$ \\
\hline
\end{tabular}

* N : Normal cellularity.

I: Increased cellularity.

D: Decreased cellularity. 


\begin{tabular}{|c|c|c|c|c|c|c|c|c|c|c|}
\hline Patient & Age & Sex & Diagnosis & $\begin{array}{l}\text { Hemo- } \\
\text { globin }\end{array}$ & $\begin{array}{c}\text { Relative } \\
\text { marrow } \\
\text { cellu- } \\
\text { larity* }\end{array}$ & $\begin{array}{c}\text { Brachial } \\
\text { artery } \\
\text { cuff } \\
\text { pressure }\end{array}$ & \multicolumn{2}{|c|}{$\begin{array}{l}\text { Sternal } \\
\text { marrow } \\
\text { pressure }\end{array}$} & \multicolumn{2}{|c|}{$\underset{\substack{\text { marroch } \\
\text { pressure }}}{\text { Iliac }}$} \\
\hline & & & & \multicolumn{2}{|l|}{ Gm. $\%$} & 115 & \multicolumn{2}{|c|}{$\mathrm{mm} . \mathrm{Hg}$} & \multicolumn{2}{|c|}{$m m . \mathrm{Hg}$} \\
\hline J. Z. & 55 & $\mathbf{M}$ & Lymphosarcoma & 8.2 & $\mathbf{N}$ & $\overline{75}$ & \multicolumn{2}{|l|}{ - } & & $\overline{6}$ \\
\hline R. M. & 23 & $\mathbf{M}$ & Hodgkin's disease & 7.9 & $\mathrm{~N}$ & 120 & \multirow{2}{*}{\multicolumn{2}{|c|}{ - }} & & 4 \\
\hline & & & & & & 70 & & & & 0 \\
\hline \multirow{2}{*}{ R.W. } & 32 & $\mathrm{M}$ & Acute lymphocytic leukemia & 6.5 & $\mathrm{I}$ & 130 & & 29 & \multirow{2}{*}{\multicolumn{2}{|c|}{ - }} \\
\hline & & & & & & 65 & & 26 & & \\
\hline I. D & $\Delta 1$ & $M$ & Acute lymohocutic loukemi & 00 & $\mathbf{I}$ & 145 & 21 & 10 & 65 & 52 \\
\hline 1. $D$. & 41 & 101 & Acute tympiocy uc teukemia & 9.0 & 1 & 90 & 0 & $\overline{-5}$ & 37 & 30 \\
\hline H. B. & 24 & $\mathbf{F}$ & Acute myeloblastic leukemia & 106 & $\mathrm{I}$ & 110 & \multirow{2}{*}{\multicolumn{2}{|c|}{ - }} & & 63 \\
\hline & & & & & & 65 & & & & 45 \\
\hline & & & & & & 118 & 60 & 50 & 57 & 45 \\
\hline R. R. & 17 & $\mathbf{M}$ & Acute myeloblastic leukemia & 8.2 & I & $\overline{80}$ & $\overline{40}$ to & $\overline{36}$ & $\overline{30}^{t}$ & 30 \\
\hline \multirow{2}{*}{ D. V. } & & & \multirow{2}{*}{ Lymphatic leukemia } & \multirow{2}{*}{9.0} & \multirow{2}{*}{ I } & 118 & & 51 & & 22 \\
\hline & 16 & $\mathbf{M}$ & & & & 80 & & 43 & & $\overline{19}$ \\
\hline \multirow{2}{*}{ C. $\mathrm{M}$. } & \multirow{2}{*}{73} & \multirow{2}{*}{ M } & \multirow{2}{*}{ Lymphatic leukemia } & \multirow{2}{*}{11.7} & \multirow{2}{*}{ I } & 145 & 6 & 2 & & 6 \\
\hline & & & & & & $\overline{65}$ & $4^{- \text {to }}$ & $\overline{0}$ & & 4 \\
\hline \multirow{2}{*}{ H. B. } & \multirow{2}{*}{68} & \multirow{2}{*}{ F } & \multirow{2}{*}{ Myelocytic leukemia } & \multirow{2}{*}{10.4} & \multirow{2}{*}{$\mathrm{N}$} & 115 & & 22 & & 13 \\
\hline & & & & & & 70 & $\overline{10}^{\text {to }}$ & 14 & & 10 \\
\hline \multirow{2}{*}{ W. F. } & \multirow{2}{*}{67} & $M$ & Mvelocytic leukemia & 126 & I & 160 & & 8 & & 21 \\
\hline & & 101 & 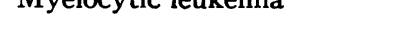 & 12.0 & 1 & 85 & & 6 & & 10 \\
\hline H. T. & 54 & M & Monocytic leukemia & 107. & $\mathbf{N}$ & 120 & - & & & 15 \\
\hline ח. 1. & 34 & 101 & Mionocy tic leukemia & 10.1 & IN & 80 & - & & & 6 \\
\hline & & & & & & 102 & & 8 & & \\
\hline R. J. & 25 & $\mathbf{M}$ & Monocytic leukemia & 9.5 & 1 & $\overline{50}$ & & $\overline{4}$ & & - \\
\hline G. C. & 57 & $\mathrm{~F}$ & Multiple myeloma & 10.5 & I & 123 & - & & & 22 \\
\hline & & & & & & 80 & & & & 14 \\
\hline
\end{tabular}

negative intrathoracic pressure produced by this maneuver. The Mueller effect was not reflected on the iliac crest pressure levels. Coughing produced decided alterations in the resting pressure. During the short inspiratory phase of the cough, a brief decrease in pressure was followed by a large brief pressure increase during the expiratory phase. The cough effect was most pronounced in the sternal site, but was frequently noted to a lesser degree in the iliac crest.
The typical effects on marrow pressure of altering body position are graphically shown in Figures 2 and 3. Readjustments in mean pressures and pulse pressure resulted from having the patient change from a recumbent position to a sitting position and again to recumbent.

Figure 3 was recorded while the subject was changing to the recumbent position from an upright position. A pronounced negative pressure resulted near the end of this act. The pressure 


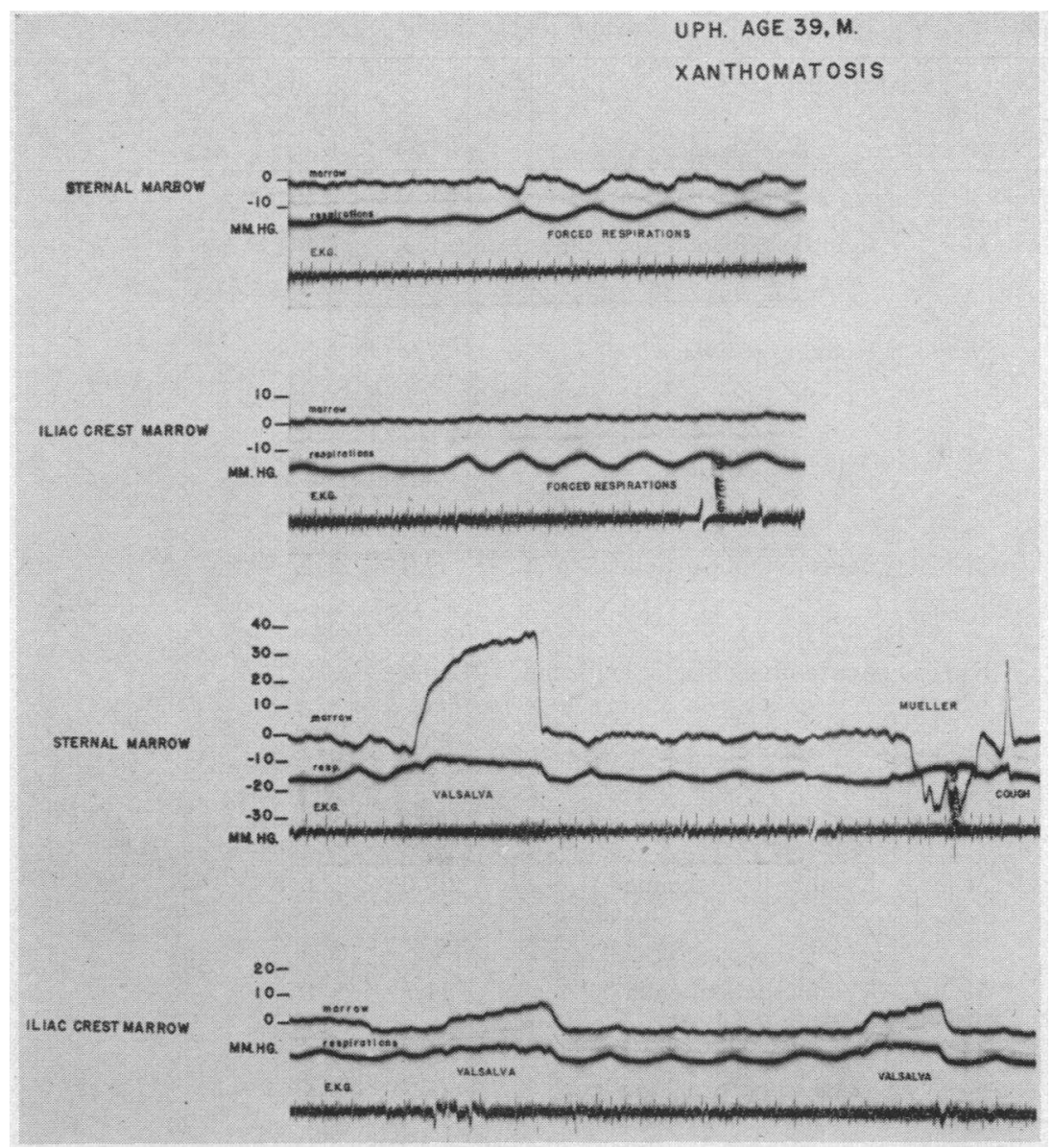

Fig. 1. Resting Pressures in Marrow of Sternum and Iliac Crest in a Patient without Hematologic Evidence of Marrow Disease

Shown are the alterations in marrow pressure produced by forced respirations, Valsalva, and Mueller maneuvers.

then rose to a level $20 \mathrm{~mm}$. $\mathrm{Hg}$ below that observed in the erect position. A progressive increase in iliac crest pressure was found to occur as the patient changed from a supine to sitting to standing and squatting positions.

The intravenous injection of $0.05 \mathrm{mg}$. epinephrine resulted in a decrease of mean pressure and diminution of pulse pressure. The sternal pressures became completely negative and showed the superimposed respiratory cycle. The iliac marrow also showed similar decreases in both mean and pulse pressures, which in no instance became negative. This effect of epinephrine was most pronounced in the leukemic subjects and is discussed below. The relative magnitudes of iliac marrow pressures and femoral artery pressure are shown in Table I in six patients.
Pulse wave analysis in the non-leukemic marrows revealed simple pulsations, except in the sternal sites where, in many patients, irregularities suggestive of venous pulsations were frequently superimposed upon the pulse waves (Figure 4 , upper and middle tracings).

\section{B. Leukemic bone marrow}

The findings in this group of patients with leukemia revealed increased pressures in both marrow sites. The greatest mean pressures and pulse pressures were found in patients with the acute leukemias. Lesser pressure elevations were found in patients with other varieties of leukemia. The responses in leukemic marrow pressure to the Valsalva and Mueller maneuvers, cough, change of 


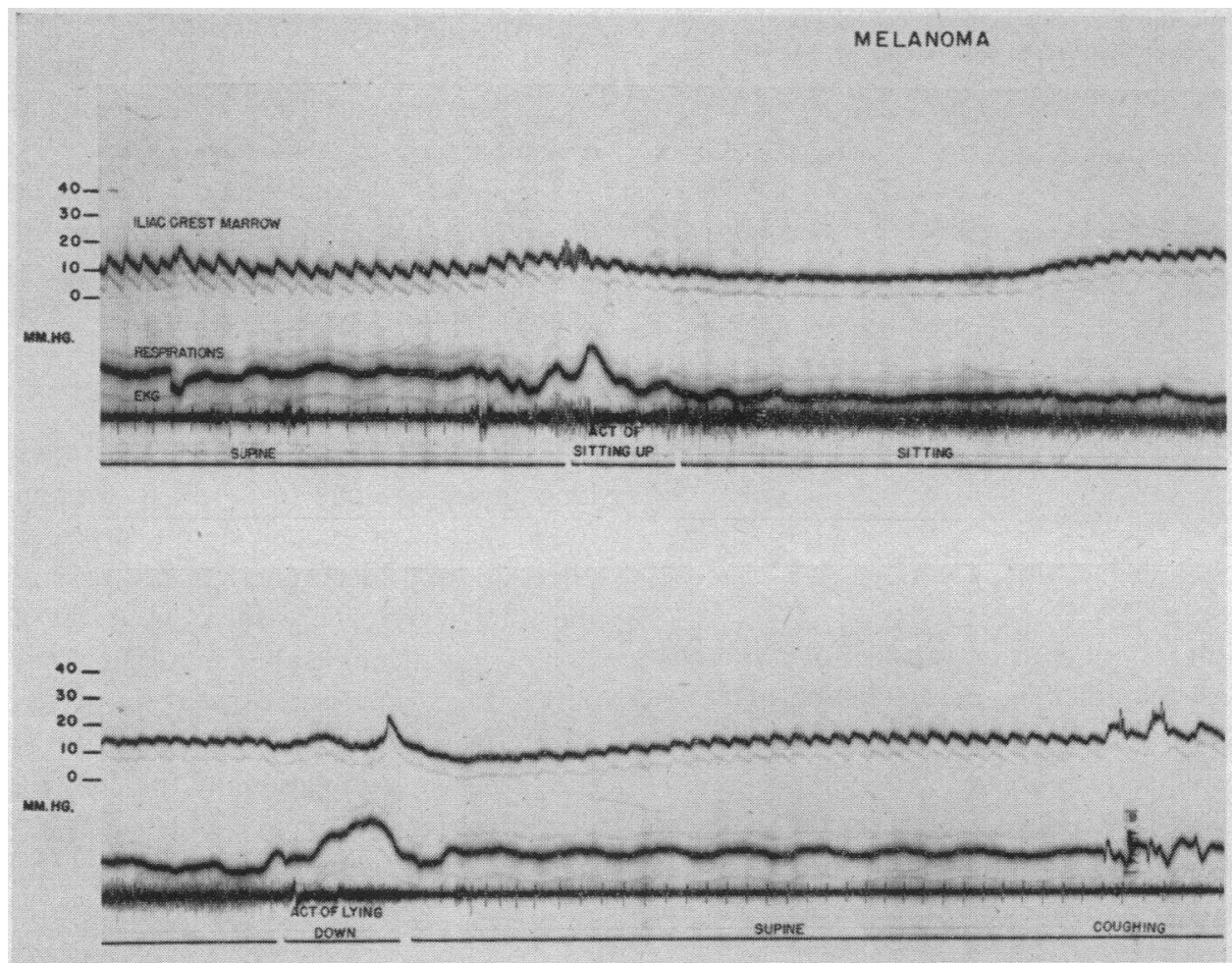

Fig. 2. Alterations in Iliac Marrow Pressure in Patient A. B. Continuously Recorded during Change of Body Position

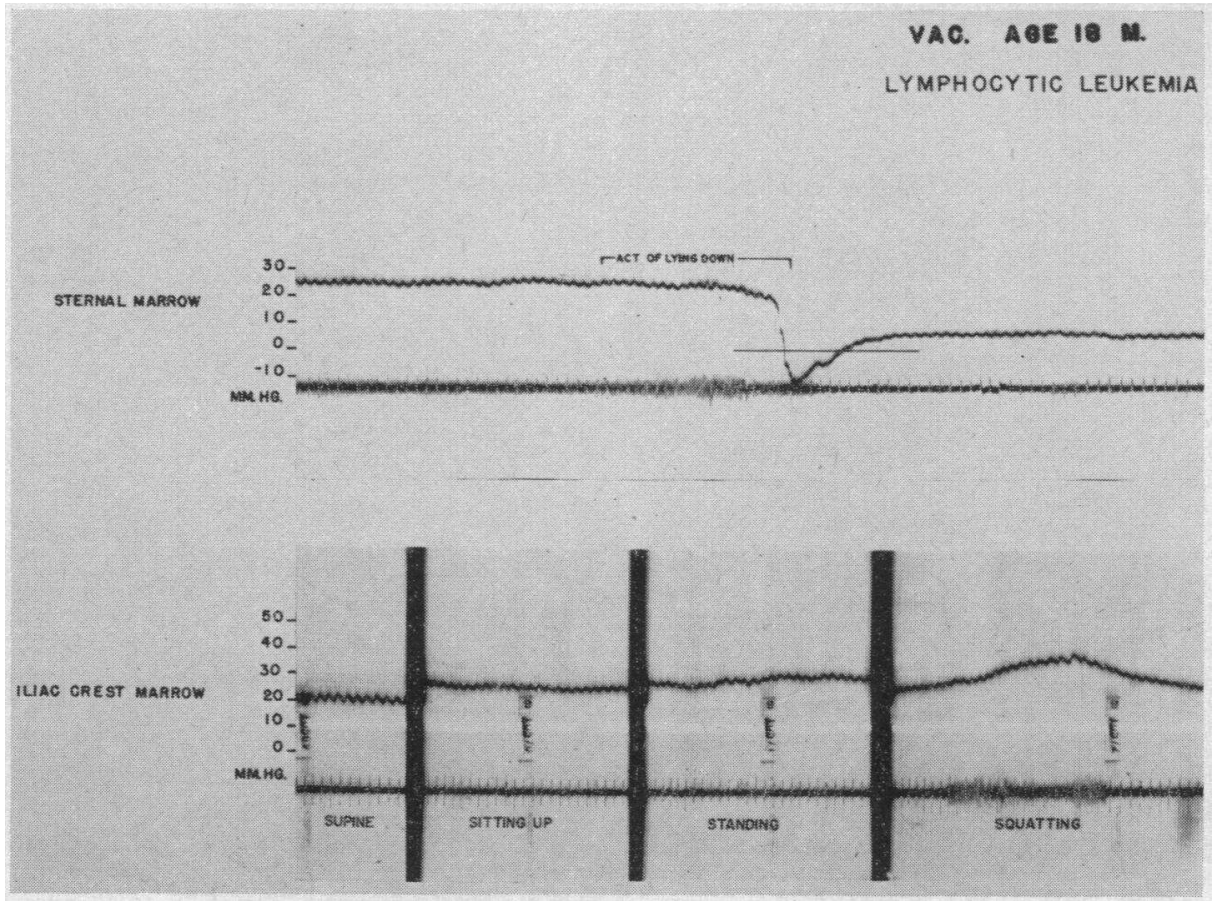

Fig. 3. Alterations in Marrow Pressure Produced by Body Position in a Patient with LEUKEMIA 


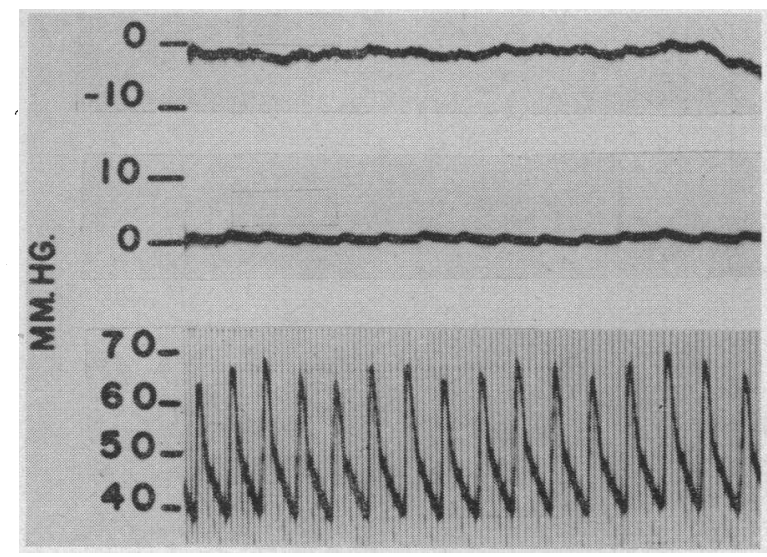

Frg. 4

position, and to epinephrine were similar in direction to those obtained in non-leukemic marrows, the difference being an exaggerated, more spectacular, response (Figure 5).

Analysis of the pulse waves in the leukemic group revealed dicrotic notching in those patients with the highest mean and pulse pressures. Figure 4 (lower tracing) shows the pulse pressure waves in patient I.D. with acute monoblastic leukemia.

There was no apparent correlation between the mean pressures and pulse pressures in the marrow and the degree of anemia within the range of hemoglobin levels in these patients (Table I).

\section{DISCUSSION}

Larsen (3) found the average pressure in the long bones of dogs to be 30 to $40 \mathrm{~mm}$. $\mathrm{Hg}$, and found that intravenously administered epinephrine, pitressin, and histamine resulted in a reduction of the total marrow pressure, while the administration of ephedrine resulted in a rise in marrow pressure. Foa (4) demonstrated the vasoconstricting effect on the marrow of epinephrine and sympathetic nerve stimulation in the long bone of the dog. Rasgon, Vater, and Marbarger (5), employing the strain gauge on long bones in dogs, con-

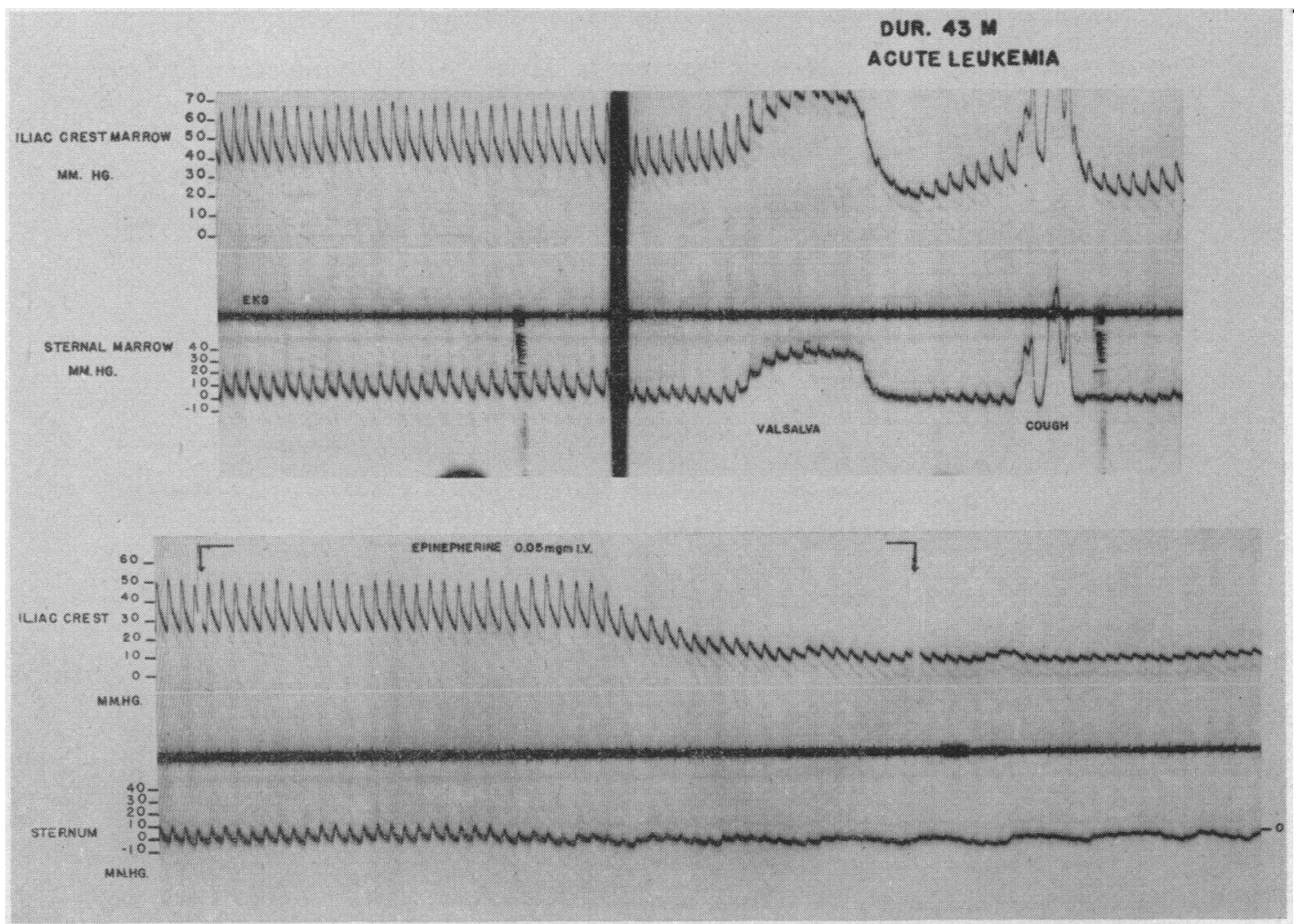

Fig. 5. Upper Figure: Typical Pressure Recording from a Patient with Acute Monoblastic Leukemia Lower Figure: Depicting the Effect of 0.05 mg. Intravenously Administered Epinephrine on Iliac Crest and Sternal Marrow Pulse Pressures 
cluded that the marrow behaves as a semi-closed cavity and that changes in the intramedullary pressure are dependent upon the volume of blood within the marrow cavity. When the venous return is obstructed, the mean pressure of the marrow increases and the pulse pressure decreases, whereas compression of the afferent arterial blood supply, mechanically or by epinephrine vasoconstriction, decreases both the mean and pulse pressures. Kalser and his co-workers (6) demonstrated a direct correlation between altitude and a fall in marrow pressure in dogs, and experimentally confirmed that the marrow cavity acts as a semi-closed cavity.

Data obtained in the present study support the interpretation of Rasgon and Kalser that the marrow cavity physiologically resembles a semi-closed cavity. The result of the Valsalva maneuver is a rise in the systemic venous pressure, thus reducing the venous outflow from the marrow cavity and producing an increase of mean marrow pressure and decreased pulse pressure. Epinephrine decreases the afferent blood flow to the marrow by constricting the nutrient arterioles, and produces a decrease in total pulse pressure in the bone marrow. The human marrow pressures were generally much lower than those found in dogs, possibly due to the effects of ether or barbital anesthesia in the dogs.

This study of respiratory alterations and of body position demonstrates the lability of the human bone marrow pressures as a result of such changes. Sternal pressures were found to be near or below atmospheric pressures in recumbent non-leukemic patients, and to vary with the amplitude of respirations. The more distal iliac sites did not respond to the respiratory effects of forced breathing, but required the more strenous effects of the Valsalva effort or coughing. The higher pressures obtained in the iliac crest are presumably a result of the erect position of man. In the patients, the mean iliac crest pressure rose with the degree of erectness, while the pressures were more variable in the sternum, and in all cases the increases in pressures were much less than in the ilium. The effects of body position and of respiratory alterations on marrow pressures indicate that under conditions of normal activity the intra-medullary pressure varies considerably and is passively affected by changes in the venous pressure resulting from these activities.

The patients with leukemia and multiple myeloma differed from non-leukemic patients in having elevated mean pressures and increased pulse pressures in the marrow cavities. In the patients with acute leukemia where the highest pressures were found, dicrotic notches were present in the pulse waves suggesting a lowered peripheral resistance in the marrow circulation in these patients. The degree of anemia present in these patients could not be correlated with the mean pressures or the pulse pressures in the marrow. These pressure data confirm the increased vascularity in the marrow in some forms of leukemia as has been previously demonstrated by the clearance of $\mathrm{I}^{131}$ from the marrow (7).

In many patients with multiple myeloma and metastatic bone lesions, distinct bone pain is associated with sudden straining or coughing. It is possible that the sudden elevation of intramedullary pressure shown to result from such effort results in distortion of the arteries and arterioles bearing sensory nerves and thus produce pain. It is also conceivable that long-continued exaggerated intramedullary arterial pulsations, in a manner analogous to the arterial notching of ribs in coarctation of the aorta, may contribute to erosion of the trabeculae frequently observed in leukemic bone marrow.

Practically no information is available regarding the hematopoietic effects of such alterations in marrow pressures as is seen in physiological and pathologic states. Drinker, Drinker, and Lund (8) were unable to dislodge cells from the marrow of dogs by continuous perfusion. Foa (4) however demonstrated that 15 minutes following the vasoconstrictive effect of epinephrine, an increase occurred in the total number and the percentage of immature cells in the venous blood draining the marrow of dogs. Comparable studies in man are lacking, but the factor of abrupt alterations in marrow pressure resulting from normal physiologic activity merits further consideration as a mechanism of blood cell delivery from the marrow in addition to such postulated factors as growth pressure and level of cell maturity $(9,10)$. The concept that the marrow tissues are sheltered from external forces in a bony cage where constant en- 
vironmental conditions prevail is not supported by the findings in the present investigation.

\section{SUMMARY}

The sternal and iliac crest bone marrow pressures of patients having neoplastic diseases and patients with leukemia were determined by means of recording strain gauges. The responses in marrow pressure were determined under a variety of physiologic stimuli. The human marrow circulation was found to be readily influenced by normal physiological variations of respiration and body position.

The alterations produced in marrow pressures in leukemic and non-leukemic patients were similar. However, markedly elevated pressures were found in leukemic patients. The significance of the findings was discussed in terms of normal and leukemic bone marrow physiology.

\section{REFERENCES}

1. Forkner, C. E., Leukemia and Allied Disorders, New York, The Macmillan Company, 1938, p. 333.

2. Bierman, H. R., and Jenkins, R., A hypodermic pressure manometer utilizing the bonded wire resistance strain gauge. Rev. Scient. Instrument, 1951, 22, 268.
3. Larsen, R. M., Intramedullary pressure with particular reference to massive diaphyseal bone necrosis. Ann. Surg., 1938, 108, 127.

4. Foa, P. P., Studies on the innervation of the bone marrow. II. Physiology. Univ. Hosp. Bull., Ann Arbor, 1943, 9, 19.

5. Rasgon, I., Vater, G., and Marbarger, J. B., cited by Kalser et al. J. Aviation Med., 1951, 22, 286.

6. Kalser, M. H., Ivy, H. K., Pevsner, L., Marbarger, J. P., and Ivy, A. C., Changes in bone marrow pressure during exposure to simulated altitude. J. Aviation Med., 1951, 22, 286.

7. Petrakis, N. L., Masouredis, S. P., and Miller, P., The local blood flow in human bone marrow in leukemia and neoplastic diseases as determined by the clearance rate of radioiodide $\left(\mathrm{I}^{131}\right)$. J. Clin. Invest., 1953, 32, 952.

8. Drinker, C. K., Drinker, K. R., and Lund, C. C., The circulation in the mammalian bone marrow; with especial reference to the factors concerned in the movement of red blood-cells from the bone marrow into the circulating blood as disclosed by perfusion of the tibia of the dog and by injections of the bonemarrow in the rabbit and cat. Am. J. Physiol., 1922, 62, 1.

9. Bunting, C. H., The regulation of the red blood cell supply in Contributions to Medical and Biological Research. Dedicated to Sir William Osler. New York, Paul Hoeber, 1919, vol. 2, p. 824.

10. Key, J. Albert, Studies on erythrocytes, with special reference to reticulum, polychromatophilia and mitochondria. Arch. Int. Med., 1948, 28, 511. 